\title{
Health Status and Food Intake Frequency of Elderly Residents During COVID-19 Community Closure - Jiangxia District, Wuhan City, China, 2020
}

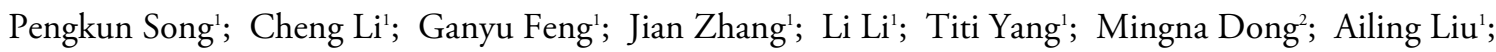

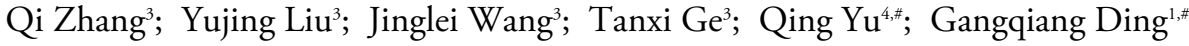

\section{Summary \\ What is already known about this topic? \\ Elderly persons are vulnerable to infectious diseases, and nutritional status and health conditions were important to evaluate for disease prevention and ability to recover for the elderly during the coronavirus disease 2019 (COVID-19) pandemic.}

\section{What is added by this report?}

In our study, a rapid assessment questionnaire was used to investigate the change of household life and dietary intake of the elderly (aged 60 years or more) during community closure. Food consumption frequency of aquatic food products, soybeans, and fresh fruits declined dramatically with reductions of $70.9 \%$, $70.9 \%$, and $53.0 \%$, respectively, and $49.6 \%$ of the elderly lived with chronic non-communicable diseases but had little knowledge of nutrition and health.

What are the implications for public health practice?

Community closure measures in Wuhan City have played a key role in cutting off the transmission route of COVID-19 and protecting vulnerable groups. As a high-risk population, the elderly should be advised to maintain and strengthen a balanced diet with proper nutrition through increasing intake of aquatic food products, soybeans, fruits, and vegetables, reducing total caloric intake, and decreasing oil and salt consumption. These measures will be significant for the elderly to reduce the risk of chronic disease complications and COVID-19 infection and to decrease the chance of critical illness.

The coronavirus disease 2019 (COVID-19) pandemic presented great physical and mental challenges for the residents of Wuhan (1). Elderly individuals aged 60 years or more were more susceptible and vulnerable to infectious diseases due to comparatively weaker immune functions and were a high-risk group in the pandemic. Except for effective personal protection, balanced diets and proper nutrition were effective means to maintain the immune function of the elderly. To assess the change of diet and health status of the elderly after community closure measures, we conducted a survey in Jiangxia District of Wuhan City, Hubei Province.

Considering the feasibility of field investigations, we selected two communities (A and B) in the Zhifang Sub-District, which had relatively strict management due to higher numbers of diagnosed cases compared to other sub-districts in Jiangxia District. The residents of the two communities were relatively concentrated; $11.6 \%$ of Community A were elderly individuals under social community management (where the community was managed by its own members) and $48.5 \%$ of Community B were elderly under factory group management (where residents had family members working in the factory, and this factory managed the community). Anonymous online surveys were conducted in Community A, and because some elderly individuals could not use smart phones, family members helped complete the online survey. Questionnaires in Community B were completed in person by trained team members.

A total of 117 questionnaires were completed from March 16 to 23, 2020 after 3 participants were excluded for being aged under 60 years. Overall, $35.9 \%$ of the questionnaires were completed independently, and $64.1 \%$ were completed by family members or community workers. SAS 9.4 software (SAS Institute Inc., Cary, NC, USA) was applied for statistical analysis. T-tests, analysis of variance, and chisquare tests were used to compare the differences among subgroups. Bilateral $p<0.05$ was considered as statistically significant.

In our survey, $45.3 \%$ of the participants were male and the ratio of genders was $1: 1.21$. The average age of the elderly was $72.2 \pm 8.5$ years (range: $60-102$ years) with a similar average age in both genders. As for education, $67.5 \%$ of the elderly had schooling of 9 
years or less (equivalent to junior high school or below), and $15.4 \%$ had schooling of 13 years and above (equivalent to a college or tertiary education). Among the older participants, the smoking rate was $16.2 \%$ (26.4\% for men and $7.8 \%$ for women). An estimated $49.6 \%$ of the elderly suffered from chronic diseases including $69.0 \%$ having hypertension and those with diabetes, osteoporosis, and tumors accounted for $15.5 \%, 15.5 \%$ and $15.5 \%$, respectively. An estimated $69.0 \%$ of surveyed individuals were chronically taking 3 or more medications. During the pandemic, $72.6 \%$ of the elderly reported that they did not pay attention to diet and nutrition, and $95.7 \%$ of the elderly did not deliberately take nutritional supplements. In our study, $21.4 \%$ of the elderly did not know their weight and $61.5 \%$ neglected waist circumference. A proportion of $15.2 \%$ in those who knew their weight reported an increased weight, while $22.2 \%$ had reductions in weight. There were statistically significant differences between gender, age, education, health status, and change of body weight between the 2 communities $(p<0.05)$ (Table 1$)$.

During the community closure period, the elderly reported that basic food and drink were mainly supplied by local community $(83.8 \%)$ and family reserves $(70.1 \%)$. There was a higher proportion of online purchasing in Community A (36.8\%) than in Community B (13.3\%) with statistically significant differences $(p<0.01)$. The elderly in Community A also reported a statistically higher proportion of food reductions $(43.9 \%)$ than in Community B (1.7\%; $p<0.01)$, and also a higher proportion of the elderly ate two meals per day or less in community A than community B $(38.6 \%$ vs. $5.0 \%$, $p<0.01)$. Furthermore, only $21.4 \%$ of the elderly met the recommended 1,500 $\mathrm{mL}$ of daily water intake (Table 1 ).

About $83.8 \%$ of the elderly consumed rice or wheat products once or more per day, and $82.1 \%$ consumed fresh vegetables more than one time a day. The proportion of the elderly who consumed red meat and poultry once a week or more was $69.2 \%$. The frequency of egg consumption of the elderly was $63.3 \%$ of at least once a day and $28.2 \%$ of $1-6$ times a week. However, the proportions of elderly consuming soybeans, milk, and aquatic food products (including freshwater fish, marine fish, shrimp, crab, shellfish and other animal aquatic products excluding seaweed, kale, etc.) less than once a week were $73.5 \%, 61.6 \%, 60.6 \%$, respectively. Red meat and poultry intake frequency of more than once a day among males was significantly higher than that in female $(52.8 \%$ vs. $34.4 \%, p<0.01)$.
Potatoes consumption frequency of more than once per day among individuals aged 80 years and above was significantly lower than that of individuals aged 70-79 years and individuals aged 60-69 years (10.7\%, $20.0 \%, 16.3 \%$; $p<0.05)$. However, there were no statistically significant differences of intake frequency of specific foods between the elderly in better health status and those living with chronic diseases. When compared with before community closures, the proportions of elderly consuming dramatically less aquatic food products, soybeans, and fresh fruit after community closures were $70.9 \%, 70.9 \%$, and $53.0 \%$, respectively. Subgroup analysis showed that the consumption of rice/wheat products and coarse grains was significantly reduced among females than in males ( rice/wheat products: $21.9 \%$ vs. $5.7 \%$, coarse grains: $46.9 \%$ vs. $24.5 \%, p<0.05)$, but healthy individuals consumption of eggs, red meat, and poultry were reportedly more significantly reduced than in individuals with chronic diseases (eggs: $22.0 \%$ vs. $6.9 \%$; red meat and poultry: $44.1 \%$ vs. $32.8 \%$; $p<0.05$ ) (Table 2).

Table 3 showed that $85.5 \%, 83.8 \%, 79.5 \%, 73.5 \%$, $70.9 \%$, and $60.7 \%$ of the elderly consumed milk, potatoes, coarse grains, soybeans, fresh fruits, and aquatic food products lower than recommended levels. Females also showed much higher rates of not consuming recommended amounts of rice/wheat products, red meat, and poultry when compared to males (rice/wheat products: $23.4 \%$ vs. $7.6 \%$; red meat and poultry: $45.3 \%$ vs. $13.2 \%$ ).

\section{DISCUSSION}

This investigation demonstrated that dietary nutrition status of the elderly was affected during the COVID-19 pandemic in Wuhan as their consumption of aquatic food products, soybeans and fresh fruits decreased significantly. Furthermore, unreasonable and unbalanced diet structure combined with decreased physical activity will increase the risk of chronic diseases. Therefore, the elderly should maintain balanced diet as well as an active lifestyle during the pandemic.

During the period of community closure in Wuhan, early of foods reservs such as rice, flour, oil, vegetables, eggs, meats, and poultry were often prioritized at the family level. These basic foods provided adequate energy and moderate levels of protein to prevent severe energy-protein malnutrition from occurring in the short term. In addition, community food supplies were 
TABLE 1. Characteristics of participants in two communities during the period of community closure.

\begin{tabular}{|c|c|c|c|}
\hline variables & Community $A(n=57)$ & Community $B(n=60)$ & Total $(n=117)$ \\
\hline Female $(\mathrm{n}, \%)$ & $37(64.9)$ & $27(45.0)^{*}$ & $64(54.7)$ \\
\hline Age (mean \pm sd) & $69.4 \pm 8.4$ & $74.8 \pm 7.7^{\dagger}$ & $72.2 \pm 8.5$ \\
\hline \multicolumn{4}{|l|}{ Age group (n, \%) } \\
\hline $60-69$ years & $31(54.4)$ & $18(30.0)^{\dagger}$ & $49(41.9)$ \\
\hline $70-79$ years & $17(29.8)$ & $23(38.3)$ & $40(34.2)$ \\
\hline 80 years and above & $9(15.8)$ & $19(31.7)$ & $28(23.9)$ \\
\hline \multicolumn{4}{|l|}{ Education level $(\mathrm{n}, \%)$} \\
\hline Primary school and below & $30(52.6)$ & $9(15.0)^{\dagger}$ & $39(33.3)$ \\
\hline Junior high school & $11(19.3)$ & $29(48.4)$ & $40(34.2)$ \\
\hline Senior high school & $6(10.5)$ & $14(23.3)$ & $20(17.1)$ \\
\hline College or other tertiary education & $10(17.6)$ & $8(13.3)$ & $18(15.4)$ \\
\hline Smoking (n, \%) & $9(15.8)$ & $10(16.7)$ & $19(16.2)$ \\
\hline Living with chronic diseases ${ }^{\S}(\mathrm{n}, \%)$ & $16(28.1)$ & $42(70.0)^{\dagger}$ & $58(49.6)$ \\
\hline Hypertension (n, \%) & $10(62.5)$ & $30(71.4)$ & $40(69.0)$ \\
\hline Diabetes (n, \%) & $4(25.0)$ & $5(11.9)$ & $9(15.5)$ \\
\hline Osteoporosis (n, \%) & $5(31.2)$ & $4(9.5)$ & $9(15.5)$ \\
\hline Tumors (n, \%) & $5(31.2)$ & $4(9.5)$ & $9(15.5)$ \\
\hline Chronic use of 3 or more medications ( $\mathrm{n}, \%$ ) & $13(81.2)$ & $27(64.3)^{*}$ & $40(69.0)$ \\
\hline Paid attention to diet and nutrition (n, \%) & $6(10.5)$ & $26(43.3)^{* *}$ & $32(27.4)$ \\
\hline Taking nutritional supplements (n, \%) & $1(1.8)$ & $4(6.7)$ & $5(4.3)$ \\
\hline Current self-reported body weight (mean \pm sd) & $59.4 \pm 14.2$ & $62.3 \pm 11.0$ & $61.0 \pm 12.5$ \\
\hline Former self-reported body weight (mean \pm sd) & $59.9 \pm 13.9$ & $63.3 \pm 11.1^{\dagger}$ & $61.8 \pm 12.4$ \\
\hline \multicolumn{4}{|l|}{ Body weight change during community closure ${ }^{\pi}$} \\
\hline No change $(\mathrm{n}, \%)$ & $15(48.4)$ & $30(73.2)^{\star}$ & $45(62.5)$ \\
\hline Weight gain $(\mathrm{n}, \%)$ & $8(25.8)$ & $3(7.3)$ & $11(15.2)$ \\
\hline Weight loss $(n, \%)$ & $8(25.8)$ & $8(19.5)$ & $16(22.2)$ \\
\hline Self-reported waist circumference (mean \pm sd) & $84.9 \pm 14.3$ & $87.7 \pm 12.3$ & $86.8 \pm 12.9$ \\
\hline \multicolumn{4}{|l|}{ Food sources $(\mathrm{n}, \%)$} \\
\hline Local community supplies & $45(79.0)$ & $53(88.3)$ & $98(83.8)$ \\
\hline Family reserves & $39(68.4)$ & $43(71.7)$ & $82(70.1)$ \\
\hline Online purchase & $21(36.8)$ & $8(13.3)^{\dagger}$ & $29(24.8)$ \\
\hline Food intake reduction during community closure $(\mathrm{n}, \%)$ & $25(43.9)$ & $1(1.7)^{\dagger}$ & $26(22.2)$ \\
\hline Consuming 2 meals per day or fewer during community closure $(\mathrm{n}, \%)$ & $22(38.6)$ & $3(5.0)^{\dagger}$ & $25(21.4)$ \\
\hline Water intake of at least $1,500 \mathrm{~mL}$ per day $(\mathrm{n}, \%)$ & $8(14.0)$ & $17(28.3)$ & $25(21.4)$ \\
\hline
\end{tabular}

: Comparison of variables between two communities, $p<0.05$.

t: Comparison of variables between two communities, $p<0.01$.

s: Chronic diseases included cardiovascular and cerebrovascular diseases, cancer, diabetes, and chronic respiratory diseases.

ॠ: The weight change was calculated among those who had known their body weights both before and after community closure.

a complementary addition for household food stocks. But due to different community management, there were differences in the variety and quantity of the food supply, which potentially influenced the food intake of the elderly. Due to limits in the food supply and insufficient intake of fresh fruits, soybeans, and aquatic food products, the elderly inevitably experienced a lack of high-quality protein, calcium, vitamins, and essential fatty acids, so increasing the variety of available food should be a priority as the communities return to normalcy. In addition, high-quality protein plays an important role in improving immunity of the 
TABLE 2. Intake frequency of specific foods and reductions* among elderly participants during the period of community closure.

\begin{tabular}{|c|c|c|c|c|c|c|c|c|}
\hline \multirow{2}{*}{ Food items } & \multicolumn{2}{|c|}{ Gender (\%) } & \multicolumn{3}{|c|}{ Age group (\%) } & \multicolumn{2}{|c|}{ Healthy status $^{\dagger}(\%)$} & \multirow{2}{*}{ Total $(\%)$} \\
\hline & Male & Female & $60-69$ years & $70-79$ years & 80 years and above & Yes & No & \\
\hline \multicolumn{9}{|l|}{ Rice/wheat products } \\
\hline$\geq$ once/day & 92.5 & 76.6 & 79.7 & 82.5 & 92.9 & 83.1 & 84.5 & 83.8 \\
\hline $1-6$ times/week & 7.5 & 12.5 & 16.3 & 10.0 & - & 11.9 & 8.6 & 10.3 \\
\hline $1-3$ times/month & - & 4.7 & 2.0 & 5.0 & - & 3.4 & 1.7 & 2.6 \\
\hline$\leq$ once/month & - & 6.2 & 2.0 & 2.5 & 7.1 & 1.6 & 5.2 & 3.3 \\
\hline Reduction & 5.7 & $21.9^{\S}$ & 14.3 & 17.5 & 10.7 & 15.3 & 13.8 & 14.5 \\
\hline \multicolumn{9}{|l|}{ Coarse grains } \\
\hline$\geq$ once/day & 24.5 & 17.1 & 22.5 & 17.5 & 21.4 & 22.0 & 19.0 & 20.5 \\
\hline 1-6 times/week & 20.8 & 26.6 & 16.2 & 37.5 & 17.9 & 15.3 & 32.8 & 23.9 \\
\hline 1-3 times/month & 17.0 & 26.6 & 28.6 & 15.0 & 21.4 & 22.0 & 22.3 & 22.2 \\
\hline$\leq$ once/month & 37.7 & 29.7 & 32.7 & 30.0 & 39.3 & 40.7 & 25.9 & 33.4 \\
\hline Reduction & 24.5 & $46.9^{\S}$ & 36.7 & 45.0 & 25.0 & 37.3 & 36.2 & 36.8 \\
\hline \multicolumn{9}{|l|}{ Potatoes } \\
\hline$\geq$ once/day & 17.0 & 15.6 & 16.3 & 20.0 & $10.7^{\S}$ & 17.0 & 15.5 & 16.2 \\
\hline $1-6$ times/week & 39.6 & 40.7 & 44.9 & 47.5 & 21.4 & 37.3 & 43.1 & 40.2 \\
\hline $1-3$ times/month & 30.2 & 28.1 & 28.6 & 27.5 & 32.1 & 30.5 & 27.6 & 29.1 \\
\hline$\leq$ once/month & 13.2 & 15.6 & 10.2 & 5.0 & 35.8 & 15.2 & 13.8 & 14.5 \\
\hline Reduction & 34.0 & 39.1 & 36.7 & 40.0 & 32.1 & 44.1 & 29.3 & 36.8 \\
\hline \multicolumn{9}{|l|}{ Fresh vegetables } \\
\hline$\geq$ once/day & 88.7 & 76.6 & 83.7 & 75.0 & 89.3 & 81.4 & 82.8 & 82.1 \\
\hline $1-6$ times/week & 11.3 & 15.6 & 14.3 & 20.0 & 3.6 & 15.3 & 12.1 & 13.7 \\
\hline 1-3 times/month & - & 6.3 & 2.0 & 5.0 & 3.6 & 3.3 & 3.5 & 3.3 \\
\hline$\leq$ once/month & - & 1.5 & - & - & 3.5 & - & 1.6 & 0.9 \\
\hline Reduction & 32.1 & 34.4 & 30.6 & 40.0 & 28.6 & 30.5 & 36.2 & 33.3 \\
\hline \multicolumn{9}{|l|}{ Fresh fruits } \\
\hline$\geq$ once/day & 32.1 & 26.6 & 32.7 & 22.5 & 32.1 & 28.8 & 29.3 & 29.1 \\
\hline 1-6 times/week & 43.4 & 32.8 & 42.9 & 37.5 & 28.6 & 33.9 & 41.4 & 37.6 \\
\hline $1-3$ times/month & 18.9 & 29.7 & 20.4 & 27.5 & 28.6 & 28.8 & 20.7 & 24.8 \\
\hline$\leq$ once/month & 5.6 & 10.9 & 4.0 & 12.5 & 10.7 & 8.5 & 8.6 & 8.5 \\
\hline Reduction & 45.3 & 59.4 & 51.0 & 60.0 & 46.4 & 52.5 & 53.5 & 53.0 \\
\hline \multicolumn{9}{|l|}{ Eggs } \\
\hline$\geq$ once/day & 71.7 & 56.3 & 63.3 & 62.5 & 64.3 & 57.6 & 69.0 & 63.3 \\
\hline 1-6 times/week & 24.5 & 31.3 & 28.6 & 27.5 & 28.5 & 33.9 & 22.4 & 28.2 \\
\hline $1-3$ times/month & 1.9 & 9.4 & 6.1 & 7.5 & 3.6 & 5.1 & 6.9 & 6.0 \\
\hline$\leq$ once/monthh & 1.9 & 3.0 & 2.0 & 2.5 & 3.6 & 3.4 & 1.7 & 2.5 \\
\hline Reduction & 7.6 & 20.3 & 16.3 & 17.5 & 7.1 & 22.0 & $6.9^{\S}$ & 14.5 \\
\hline \multicolumn{9}{|l|}{ Aquatic food products ${ }^{* *}$} \\
\hline$\geq$ once/dayy & 11.3 & 9.4 & 10.2 & 10.0 & 10.7 & 11.9 & 8.6 & 10.3 \\
\hline $1-6$ times/week & 35.9 & 23.4 & 30.6 & 25.0 & 32.1 & 32.2 & 25.9 & 29.1 \\
\hline 1-3 times/month & 39.6 & 39.1 & 38.8 & 42.5 & 35.8 & 33.9 & 44.8 & 39.2 \\
\hline$\leq$ once/month & 13.2 & 28.1 & 20.4 & 22.5 & 21.4 & 22.0 & 20.7 & 21.4 \\
\hline Reduction & 67.9 & 73.4 & 71.4 & 75.0 & 64.3 & 66.1 & 75.9 & 70.9 \\
\hline
\end{tabular}


TABLE 2. (Continued)

\begin{tabular}{|c|c|c|c|c|c|c|c|c|}
\hline \multirow{2}{*}{ Food items } & \multicolumn{2}{|c|}{ Gender (\%) } & \multicolumn{3}{|c|}{ Age group (\%) } & \multicolumn{2}{|c|}{ Healthy status $^{\dagger}(\%)$} & \multirow{2}{*}{ Total $(\%)$} \\
\hline & Male & Female & $60-69$ years & $70-79$ years & 80 years and above & Yes & No & \\
\hline \multicolumn{9}{|l|}{ Red meat and poultry } \\
\hline$\geq$ once/day & 52.8 & $34.4^{\pi}$ & 42.9 & 40.0 & 46.4 & 35.6 & 50.0 & 42.7 \\
\hline 1-6 times/week & 34.0 & 20.3 & 30.6 & 22.5 & 25.0 & 30.5 & 22.4 & 26.5 \\
\hline 1-3 times/month & 7.6 & 31.3 & 20.4 & 20.0 & 21.4 & 18.6 & 22.4 & 20.5 \\
\hline$\leq$ once/month & 5.6 & 14.0 & 6.1 & 17.5 & 7.2 & 15.3 & 5.2 & 10.3 \\
\hline Reduction & 34.0 & 42.2 & 40.8 & 37.5 & 35.7 & 44.1 & $32.8^{\S}$ & 38.5 \\
\hline \multicolumn{9}{|l|}{ Milk } \\
\hline$\geq$ once/day & 20.8 & 9.4 & 14.3 & 7.5 & 25.0 & 11.9 & 17.2 & 14.5 \\
\hline $1-6$ times/week & 22.6 & 25.0 & 22.5 & 25.0 & 25.0 & 20.3 & 27.6 & 23.9 \\
\hline 1-3 times/month & 20.8 & 23.4 & 26.5 & 25.0 & 10.7 & 20.3 & 24.1 & 22.2 \\
\hline$\leq$ once/month & 35.8 & 42.2 & 36.7 & 42.5 & 39.3 & 47.5 & 31.1 & 39.4 \\
\hline Reduction & 24.5 & 45.3 & 38.8 & 40.0 & 25.0 & 39.0 & 32.8 & 35.9 \\
\hline \multicolumn{9}{|l|}{ Soybeans } \\
\hline$\geq$ once/day & 9.4 & 3.1 & 6.1 & 2.5 & 10.7 & 6.8 & 5.2 & 6.0 \\
\hline 1-6 times/week & 24.5 & 17.2 & 22.5 & 17.5 & 21.4 & 23.7 & 17.2 & 20.5 \\
\hline 1-3 times/month & 39.6 & 32.8 & 30.6 & 42.5 & 35.7 & 33.9 & 37.9 & 35.9 \\
\hline$\leq$ once/month & 26.5 & 46.9 & 40.8 & 37.5 & 32.2 & 35.6 & 39.7 & 37.6 \\
\hline Reduction & 69.8 & 71.9 & 73.5 & 80.0 & 53.6 & 64.4 & 77.6 & 70.9 \\
\hline
\end{tabular}

TABLE 3. Elderly participants failing to reach the recommended intake levels of specific foods during the period of community closure* $(\%)$

\begin{tabular}{|c|c|c|c|c|c|c|c|c|}
\hline \multirow{2}{*}{ Food items } & \multicolumn{2}{|c|}{ Gender } & \multicolumn{3}{|c|}{ Age group } & \multicolumn{2}{|c|}{ Healthy status $^{\dagger}$} & \multirow{2}{*}{ Total } \\
\hline & Male & Female & $60-69$ years & $70-79$ years & 80 years and above & Yes & No & \\
\hline Rice/wheat products & 7.6 & $23.4^{\S}$ & 20.4 & 17.5 & 7.1 & 17.0 & 15.5 & 16.2 \\
\hline Coarse grains & 75.5 & 82.8 & 77.6 & 82.5 & 78.6 & 78.0 & 81.0 & 79.5 \\
\hline Potatoes & 83.0 & 84.4 & 83.7 & 80.0 & 89.3 & 83.1 & 84.5 & 83.8 \\
\hline Fresh vegetables & 11.3 & 23.4 & 16.3 & 25.0 & 10.7 & 18.6 & 17.2 & 18.0 \\
\hline Fresh fruits & 67.9 & 73.4 & 67.4 & 77.5 & 67.9 & 71.2 & 70.7 & 70.9 \\
\hline Eggs & 28.3 & 43.8 & 36.7 & 37.5 & 35.7 & 42.4 & 31.0 & 36.8 \\
\hline Aquatic food products ${ }^{\pi}$ & 52.8 & 67.2 & 59.2 & 65.0 & 57.1 & 55.9 & 65.5 & 60.7 \\
\hline Red meat and poultry & 13.2 & $45.3^{* *}$ & 26.5 & 37.5 & 28.6 & 33.9 & 27.6 & 30.8 \\
\hline Milk & 79.3 & 90.6 & 85.7 & 92.5 & 75.0 & 88.1 & 82.8 & 85.5 \\
\hline Soybeans & 66.0 & 79.7 & 71.4 & 80.0 & 67.9 & 69.5 & 77.6 & 73.5 \\
\hline
\end{tabular}

*: the recommended intake frequency of rice/wheat products, coarse grains, potatoes, fresh vegetables, fresh fruits, eggs, and milk were more than once a day, while intake of aquatic products, red meat, poultry, and soybeans of more than once a week were defined as meeting the recommendations.

t: Health status was defined as whether the elderly were living with chronic diseases.

\$: Comparison of each variable in different subgroups, $p<0.05$.

ף: Aquatic food products included freshwater fish, marine fish, shrimp, crab, shellfish and other animal aquatic products excluding seaweed, kale, etc.

${ }^{*}$ : Comparison of each variable in different subgroups, $p<0.01$. 
elderly during the pandemic (2). Fish, poultry, eggs, milk, lean meat, and soybean products are primary sources of high-quality protein, but marinated/ processed fish and meat products should be avoided for the potential of increasing cardiovascular disease risk in the elderly.

Elderly individuals often suffer from hypertension, diabetes, or other non-communicable cardiovascular diseases and must take multiple medications regularly. They paid more attention to their health in case of emergencies, so drug stockpiles and medical resources should always be prioritized by themselves or by the community (3). However, their nutritional status was often neglected, and food intake correspondingly decreased, especially when combined with digestive dysfunction and loss of appetite during the pandemic. For elderly with hypertension or diabetes, adequate coarse grains, vegetables, and soybeans could benefit for their blood glucose and blood pressure (4-5). Chinese dietary guidelines also recommended that a daily diet should contain an adequate amount of these plant-based foods (2).

There are some limitations in our study. First, although there was variation in age, gender, education, lifestyles, and other characteristics of the elderly involved in our study, findings from this survey were not representative of the elderly living in closed communities in Wuhan. Second, given the selfreported information nature of this survey, the results were subjected to some level of recall bias or mistakes. Third, data in this study were based on information provided by participants, so the results were also influenced by some level of subjectivity. Nevertheless, the study reflected the nutritional and health status of the elderly during the COVID-19 pandemic and can be used to inform elderly individuals' health maintenance and promotion in Wuhan.

doi: $10.46234 / \mathrm{ccdcw} 2020.120$

\# Corresponding authors: Qing Yu, yuqing@nipd.chinacdc.cn; Gangqiang Ding, dinggq@chinacdc.cn.

\begin{abstract}
National Institute for Nutrition and Health, Chinese Center for Disease Control and Prevention. Beijing, China; ${ }^{2}$ Jiangxia Disease Control and Prevention Center, Hubei, China; ${ }^{3}$ Chinese Center for Disease Control and Prevention, Beijing, China; ${ }^{4}$ National Institute of Parasitic Diseases, Chinese Center for Disease Control and Prevention (National Center for International Research on Tropical Diseases); Key Laboratory of Parasite and Vector Biology, National health and Family Planning Commission; WHO Collaborating Center for Tropical Diseases, Shanghai, China. .
\end{abstract}

Submitted: April 28, 2020; Accepted: June 15, 2020

\section{REFERENCES}

1. World Health Organization. Report of the WHO-China joint mission on coronavirus disease 2019 (COVID-19), February 16-24, 2020. https://www.who.int/docs/default-source/coronaviruse/who-china-jointmission-on-covid-19-final-report.pdf. [2020-04-28].

2. Chinese Nutrition Society. Dietary guideline of the elderly in China 2016. Beijing: People's Medical Publishing House, 2016 . (In Chinese).

3. Wu J. An important but overlooked measure for containing the COVID19 epidemic: protecting patients with chronic diseases. China CDC Weekly 2020; 2(15): 249-50. http://weekly.chinacdc.cn/en/article/id/ 45571a77-8d7a-4c78-82cb-463c72f0e7c8.

4. Micha R, Shulkin ML, Peñalvo JL, Khatibzadeh S, Singh GM, Rao M, et al. Etiologic effects and optimal intakes of foods and nutrients for risk of cardiovascular diseases and diabetes: systematic reviews and metaanalyses from the Nutrition and Chronic Diseases Expert Group (NutriCoDE). PLoS One 2017; 12(4): e0175149. https://www.ncbi. nlm.nih.gov/pmc/articles/PMC5407851/.

5. Bechthold A, Boeing H, Schwedhelm C, Hoffmann G, Knüppel S, Iqbal $\mathrm{K}$, et al. Food groups and risk of coronary heart disease, stroke and heart failure: a systematic review and dose-response meta-analysis of prospective studies. Crit Rev Food Sci Nutr 2019; 59(7): 1071-90. https://pubmed.ncbi.nlm.nih.gov/29039970/. 